\title{
Social work clinical leadership in allied health
}

\author{
Kim Fry
}

Kim Fry is the Allied Health Director and Professional Adviser for Social Work for MidCentral Health, a division of the MidCentral District Health Board. She has worked in health for the majority of her social work career.

\begin{abstract}
One of the main issues in the health environment today is the need for clinical leadership. This includes the leadership of social work within the grouping 'allied health'. Over recent years Allied Health Directors have emerged within District Health Boards (DHBs) and the author currently holds one of these positions and is the only social worker to do so. Social workers are the largest profession within the allied health group and have the knowledge, skills and attributes to provide direction within this group of many different professions. The challenges of defining and uniting allied health provides social workers with many opportunities, however we need to market and position ourselves strategically in our organisations. This article provides a case study of the Allied Health Director role at MidCentral Health and will examine how the role came about, the context of the organisation and the organisation's current structure. Key issues in defining allied health will be explored including the tensions and concerns among professionals of being viewed as a generic group. There are challenges and opportunities for social work within the health environment and this brief paper explores how we can both utilise and develop our skills, knowledge and practice to provide allied health with unity and direction.
\end{abstract}

\section{Background}

The role of Allied Health Director (AHD) within MidCentral Health was developed during a review and reorganisation of the service in June 2007. The role was one of two new clinical leadership roles, the other being a Midwifery Director, introduced to sit alongside the already well-established positions of Medical Director, the Director of Nursing and the Maori Health Manager. All positions report to the General Manager of the provider arm of the MidCentral DHB and this role development was initiated through the advocacy of allied health leaders themselves. While there are now six AHD roles throughout New Zealand each has a different reporting structure. Previously allied health input into strategic and clinical leadership was through a management structure alone, where the professional and clinical voice of allied health was rarely heard. The development of these senior roles was seen as positive for the professional groups and the organisation.

\section{Who is in 'allied health'?}

Allied health staff make up $11 \%$ of all DHB employees within New Zealand and social work is the largest group comprising of over 1,000 people (District Health Boards New Zealand, 
2008). When the AHD role was developed at MidCentral Health one of the initial tasks for the role was to develop an accepted definition of 'Allied Health'. This definition was needed for several reasons, firstly to provide management and leadership with a clear description of who this group comprises in order to easily identify when the AHD should be consulted. The second reason was to formulate a strategic vision and plan for allied health, thus to be part of the wider organisation's planning and development building unity among those groups identified (Dawson, 2006). Finally, the definition would provide focus, direction and embed the AHD role as it was (and still is) a part time position.

Two years later, a definition has still not been developed and this is because defining 'Allied Health' is difficult and complex for several reasons. Firstly, there is no national or international definition of 'Allied Health'. Two major national sector groups, District Health Boards New Zealand (DHBNZ) and Allied Health Professional Associations Forum (AHPAF) have different definitions of which professions are encompassed by allied health. Different groups devise different definitions for diverse reasons as there are multiple stakeholders who require the definition: professionals, managers and leaders within the organisation. A common concern is that any definition developed may be seen as final. This is not the case and any attempt should instead be seen as a definition for this organisation at this point in time (R. Boyce, personal communication, December 18, 2008). An explicit definition can and should be contested and debated as it cannot be static within a constantly changing health environment. One of the tensions definitions produce is that inevitably some groups will not be included and those who are 'out' will want to be 'in' and potentially visa versa (Boyce, 2008).

An additional difficulty in defining allied health is that creating a definition does not equal identity; for group identity is more than just a matter of definition (Boyce, 2008). Just using the term allied health does not mean that it is embraced by all; rather during times of constant change, individual practitioners will identify more with their professional groups than with the organisation, and perceived threats from structural change tend to heighten this identification (Callen, et al., 2007). Relating to this is what Boyce (1997) termed the 'tyranny of tribalism' whereby professional groups' primary identification and focus is on their own profession in relation to clinical practice and they do not want to belong to the larger 'nation' of allied health (Boyce, 1997, p.80).

There may also be an assumption that all the allied health professions are homogenous and have the same concerns, issues or viewpoints. However, it is clear that, for example, Profession A + Profession B + Profession $C \neq$ 'Allied Health'. The terms 'profession' and 'allied health' must be recognised as different as well and it needs to be stressed that professional titles, for example 'physiotherapy', 'occupational therapy', 'social work' relate to the clinical domain while the term 'allied health' operates at management and policy domains (Boyce, 2006, p.30).

AHD positions are still in their infancy nationally and the roles and the concept of allied health as an entity is sometimes compared to the better-established nursing and medical professions. However, using these two professional groups as comparisons is not relevant because the individual allied health groups have different histories and different issues (Jones \& Jenkins, 2006). The challenge to allied health is unique as we do not have commonalities such as an undergraduate education with shared components. 
However, the value of a clear identity for allied health ultimately means individual professions will have more influence together than alone. The challenge is building commonality from diversity while still maintaining and respecting professions' individual identity. An accepted definition will engage diverse professional groups to work towards developing an identity of being allied to each other rather than allied (or supplementary) to medicine, which is the history of many of the professions (Boyce, 1997; Jones \& Jenkins, 2006).

\section{Challenges and opportunities for social work}

So where does social work sit within this diverse group called allied health? Is this our natural home, as for example in the United Kingdom, social workers are not part of 'allied health' (Jones \& Jenkins, 2008). One of the main challenges to hospital social work is that hospitals are dominated by the medical model which conflicts with our models of practice (Woodward, 2001). Hospitals have been described as 'host' settings which are dominated, defined and managed by people who do not come from social work backgrounds (Auslander, 2000; Dane \& Simon, 1991). Our challenge is how to survive in an '... ecosystem that does not naturally support social work life' (Silverman, 2008, p. 89). The values of the hospital organisation also provides tension for social workers and often our values, mission and ethics such as client self determination, social justice and working with marginalised groups are in contrast with the predominant organisational goals and values (Dane \& Simon, 1991; Dziegielewski, 2004; Gregorian, 2005; Neuman, 2000).

Social workers often talk about their work being unseen, behind the scenes and based on relationship and rapport building with not just clients and their families but staff too. This lack of visible skills and concrete evidence of our worth makes our positions vulnerable in the present climate where outcomes and evidence of effectiveness are prized (Kayser, Hansen \& Groves, 1995). We are not alone in this vulnerable position, as despite our allied health colleagues having had more exposure to the medical model. In fact this common observation of medical dominance, being a non-nurse and feeling invisible in the hospital can unite us and ' ... the overarching concept of medical dominance continues to be an important theoretical and structural element in a contemporary understanding of the positions of the allied health professions' (Boyce, 1997, p.77). There are additional differences between the professional groups such as length of training, pay scales, influence on patients' direct care and registration of the professions that can cause power dynamics.

With these cautions in mind, what can we offer to our larger collective group of allied health? Firstly, social work needs to examine the models and theories imbedded in our profession. Common social work approaches such as systems theory, solution-based approaches and person-centred care, all now appear in health organisations and management language. Globerman (1999) maintains that this thinking represents a paradigm shift for hospital management and notably 'is second nature for social work but not for medicine, physiotherapy or occupational therapy, and only somewhat for nursing' (Globerman, 1999, p.17).

Systems theory can be employed to understand our organisational environment as it assists us to break down barriers and silos that appear in hospital organisations (Silverman, 2008). These skills can be utilised to examine the allied health role in the hospital systems - where can we and our allied health colleagues add value to the patient's 
journey? Our understanding of the 'person in environment' and the biopsychosocial approach contribute awareness that an individual's involvement with a hospital is only part of their life journey and that they are part of a family and community beyond their status as patient or client (Dane \& Simon, 1991; Dziegielewski, 2004; Woodward, 2001). On this journey through hospital settings allied health staff work along the pathways of care and 'are ideally and uniquely placed, therefore, to challenge and change the structural barriers that may exist and impact negatively on the patient's experiences of care'(Pond, 2006, p.111).

The second skill and resource that we have as social workers is our commitment to relationships and connecting with others (Bland \& Renouf, 2001). Developing, cultivating and maintaining relationships are vital to working in hospital social work. Indeed positive individual relationships at the 'front lines' or at managerial levels can have far reaching benefits and can '... often determine the status and scope of social work practice within the institution' (Gregorian, 2005, p. 9). Hospital social workers work in multi-disciplinary teams and as such can utilise their knowledge and skills in group-work, managing conflict and understanding power within teams to assist with the team's purpose (Bland \& Renouf, 2001; Woodward 2001; Coulshed, Mullender, Jones \& Thompson, 2006). Mueller and Neads (2005) while identifying the benefits of this type of team work for the allied health clinicians themselves as well as for the patient, also point out that our different histories and status (real and perceived) can cause tension and that we must acknowledge these.

Social workers have a clear commitment to political action and again an analysis of the greater forces that affect hospital care beyond the organisation we work for. Alongside this, social workers need to understand the power of informal relationships and structures that operate within hospital organisations and to develop alliances of influence, especially in times of restructuring (Dane \& Simon, 1991; Murdoch, 2007). Social workers must utilise our relationship building skills to assist in building a collective, unified allied health group in order to influence the organisation's management (Boyce, 2006; Jones \& Jenkins, 2006).

\section{Conclusion: The future for social work and allied health}

The National Government has made several clear statements about the need for clinical leadership within DHBs including developing a task force report 'In Good Hands' (Ministry of Health, 2009). The document proposes the adoption of the UK National Health Service's model of clinical leadership for New Zealand health services. This model clearly provides allied health and social work opportunities to step up and actively participate in clinical leadership and governance (Pond, 2006). Traditionally, social workers are not good at promoting ourselves and are more likely to downplay our role for fear of being self serving (Globerman, 1999). However, we must not sit back and let others do this for us or we risk being defined by those who do not know the depth and breadth of our profession. 'What is needed is that we lead, market and ultimately 'brand' social work with a strategic, skillbased approach that starts where the client is' (Silverman, 2008, p.90).

Allied health professionals need to have an identity, a leader, and a strategic vision as a group, if it is to be an indispensible part of the organisation's planning, policy and progress (Dawson, 2001, p.19). 


\section{References}

Allied Health Professionals Association's Forum. www.ahpaf.wellington.net.nz

Auslander, G. (2000). Outcomes of social work intervention in health settings. Social Work in Health Care, 31(2), 31-46.

Bland, R., \& Renouf, N. (2001). Social work and the mental health team. Australasian Psychiatry, 9(3), $238-241$.

Boyce, R. (1997). Health sector reform and professional power, autonomy and culture: The case of Australian allied health professions. In R. Hugman, M. Peelo, \& K. Soothill (Eds.), Concepts of care developments in health and social welfare (pp. 74-98). London: Edward Arnold.

Boyce, R. (2006). Using organisation as a strategic resource to build identity and influence. In R. Jones \& F. Jenkins (Eds.), Managing and leading in allied health (pp. 85-99). Oxford: Radcliffe Publishing.

Boyce, R. (2008). Why 'allied health works: Building sustainable futures. Keynote address, Inaugural New Zealand Allied Health Conference, Auckland.

Callen, V. J., Gallois, C., Mayhew, M. G., Grice, T. A., Tluchowska, M., \& Boyce, R. (2007). Restructuring the multiprofessional organisation: Professional identity and adjustment to change in a public hospital. Journal of Health and Human Services Administration, Spring, 448-477.

Coulshed, V., Mullender, A., Jones, D., \& Thompson, N. (2006). Management in social work (3rd ed.). Hampshire: Palgrave Macmillan.

Dane, B. O., \& Simon, B. L. (1991). Resident guests: Social workers in host settings. Social Work, 36(3), 208-213.

Dawson, D. (2001). Carving an identity for allied health. Australian Health Review, 24(4), 119-127.

District Health Boards New Zealand. (2008). HWIP base data report (snapshot as at 30 September 2008). Retrieved 14 April 2009 from http:/ / www.dhbnz.org.nz/Site/Future_workforce/HWIP/DHB_Base_Data_Reports.aspx

Dziegielewski, S. F. (2004). The changing face of health care social work: Professional practice in managed behavioural health care. New York: Springer Publishing.

Globerman, J. (1999). Hospital restructuring: Positioning social work to manage change. Social Work in Health Care, 28(4), 13-30.

Gregorian, C. (2005). A career in hospital social work: Have you got what it takes? Social Work in Health Care, 40(3), $1-14$.

Jones, R. \& Jenkins, F. (2006). Development and significance of the profession in AHP management. In R. Jones \& F. Jenkins (Eds.), Managing and leading in allied health (pp. 32-44). Oxford: Radcliffe Publishing.

Jones, R. \& Jenkins, F. (2008). Developing roles for allied health: Sharing experiences. Paper presented at the Inaugural Allied Health Conference, Auckland.

Kayser, K., Hansen, P. \& Groves, A. (1995). Evaluating social work practice in a medical setting: How do we meet the challenges of a rapidly changing system? Research on Social Work Practice, 5(4), 485-500.

Ministry of Health, (2009). Clinical leadership 'in good hands'. Media release 13 March 2009.

Mueller, J. \& Neads, P. (2005). Allied health and organisational structure: Massaging the organisation to facilitate the outcomes. NZ Journal of Physiotherapy, 33(2), 28-34.

Murdoch, A. (2007). Living in the trenches: Managerial skills for practitioners. Social Work, 52(4), 375-377.

Neuman, K. (2000). Understanding organisational reengineering in health care: Strategies for social work's survival. Social Work in Health Care, 31(1), 19-33.

Pond, C. (2006). Leadership in the allied health professions. In R. Jones \& F. Jenkins (Eds.), Managing and leading in allied health (pp.100-116) Oxford: Radcliffe Publishing.

Silverman, E. (2008). From ideological to competency-based: The rebranding and maintaining of medical social work's identity. Social Work, 53(1), 89-91.

Woodward, P. (2001). Mental health and social work. In M. Connolly (Ed.), New Zealand social work (pp.168-180). Oxford: University Press. 